\title{
QUALITY CONTROL AND PERFORMANCE IN ACCOUNTING
}

\author{
Professor PhDVictor Munteanu, munteanu@rau.ro, \\ The Romanian-American University, Bucharest
}

\begin{abstract}
Starting from the premise that the majority of the decision-making processes of the enterpise are using accounting information, measuring accounting quality has become a highly important issue at present.

International accounting standards contain essential elements regarding qualitative characteristics of the accounting information.

The documents of systhesis and accounting reporting manage thus to offer understandable, relevant, and believable and comparable information to a multitude of users. The accounting performance criterion, a faithful image becomes thus the upshot of the accounting quality.

An active role in this effort pertains to the accounting profession, by means of conceiving and spreading adequate practices in the field.
\end{abstract}

\section{Normalizing the quality in accounting}

The measurement of acounting quality starts from the premises according to which the accounting information tends to lose its absolute character, becoming a merchandise which can be traded. Economic theory shows that the value of an asset or a commercial service is established function of the usefulness (satisfaction) brought to the consumer. This reasoning applies to the production and communication of accounting information. Whatever the finality and the means of communication may be, the satisfaction of the needs of the user must be measured and provided on a regular basis. Developing the quality measures within the companies which produce goods and services, meets the goal of developing the trust of the consumer in the quality of information. The satisfaction of the consumer is guaranteed by means of quality control systems within companies.

\subsection{The concept of ,quality service” in accounting}

The place of services in modern economy has become considerable. They have gone beyond industry and agriculture a long time ago, being the main jobs providers and creators of added value. Lately, the techniques of managing information, commercial and non-commercial services have developed considerably. The current evolutaion forecasts a „network civilisation”, in which the main merchandise subjected to exchange shall be the information.

Like other domains of human knowledge and activity, it doesn't escape this trend of interconnection between issuers and users. A reflection of the means of continually guaranteeing the services in this field. In enterprises the relations between the accounting service and the other internal actors which participate in the administration are redefined. We can speak in this case about the structuring of an information management system in each economic entity. The exchange of the data, the development of management facilities, the multiplication of telematic services of databanks accessible to various users categories, are manifestations which lead to the necessity of reassuring ," the information consumer" as well as the carrying out of systematic checkings over the reality of the data acquired.

- How is identified the ,,accounting product”, placed at the disposal of the user? Is it possible to define the noticeable characteristics which allow normalizing the expected results?

- Independently from respecting determinable objectives, the quality of the performance offered by the accounting function involves the use of pre-established reference points regarding the methods, operational or organisational processes.

- Is it possible to set these reference points in accounting? Does internal control offer a sufficient answer to this question? 
- How can the relation client- supplier be approached, in the field of communicating accounting information for founding a system of ensuring accounting quality?

- Is there a representative quality level for the trust of the user in the nature of this information and according to which control mechanisms can we check the compliance of this information?

\subsection{Understanding quality charactersitics}

The study of the quality -related goals in enterprises, including the role of the main public and private actors which accompany them, allow the summarising of the methods of obtaining the trust of the user in the quality of services.

\begin{tabular}{|l|l|l|}
\hline Measurement instruments & \multicolumn{1}{|c|}{ Norms } & \multicolumn{1}{c|}{ Quality management methods } \\
\hline Certification & $\begin{array}{l}\text { Products - services } \\
\text { Methods }\end{array}$ & $\begin{array}{l}\text { Quality insurance } \\
\text { (ISO 9000) }\end{array}$ \\
\hline Internal control & $\begin{array}{l}\text { Decisions } \\
\text { Quality insurance }\end{array}$ & Total quality \\
\hline
\end{tabular}

\subsection{Normalizing quality management}

Independently from the regulations and the control of the implementation, the two methods of quality development are the normalization and the quality management methods.

The effort of the enterprises for the development of the trust of the users of the product or the service is expressed first of all by defining the norms. These can be norms for means, tools, methods, competences, products- services etc.

Recently, American and Japanese scholars have defined, perfected and implemented quality management methods.

From the quality of individual work, the methods imply the organisation of the quality function of the enterprise, defining the procedure, control methods, internal control for repairing the elements which lack quality. The totality of decisions applied in a company can lead to quality insurance, which allows testing the reliability of the quality-obtaining system.

The concept of total quality proves its effectiveness, by using a method which uses quality techniques. We can speak about a global management method, which makes quality the main objective and reference of all the functions and activities in the enterprise.

\subsection{Quality certification: internal control and certification by a third party}

Whatever may be the methods for obtaining quality, effectiveness and permanence of functioning of the quality system applied in the company, they cannot be provided to the user of the service without a controlled and highly quantifyable system.

The last goal whose quality system is represented by the functioning set through internal control mechanisms, oriented towars the permanent search of progress and improving performances.

However, under certain circumstances, there may be required complementary operations to the service providers, consisting of estimations regarding service evaluations.

The client may request a proof of relaibility of the quality of information. This request shall be provided by a third party, independent from the client and supplier. We are describing the certification by a third party, certifications of products, services, including enterprise certification.

Product certification is the document by means of which a third party guarantees the conformity of certain products to a pre-established tender dossier. It has as a purpose affirming the quality of the product, influencing the purchase decision of the client. 
Enterprise certification apperaed later than product certification, as a consequence of the development of the idea of quality insurance. It has as a goal the safety and constance of quality of products or services placed at the disposal of the user.

This certification has its origins in the military field, in which purchases repetitivity and the orientation of reliability make such a tool very useful. Subsequently extended to a high number of sectors of activity, it applies to the enterprises which allow a quality insurance system, offering the proof of the opinion of an independent expert about the capacity of a production system to permanently generate the expected level of quality. Its success benefitted from applying the international norms of the ISO 9000 series and represents a certification mechanism regarding quality insurance.

\subsection{Accounting information: normalization and certification of accounts}

The normalization of the accounting field is rela tively extended. It included rules regarding: registration, presentation, evaluation and regulated information, published by enterprises. The control of the competences of the professionals who exercise accounting activities (accounting expertise) is also a goal.

The certification of annual accounts is similar to the indicated quality certification mechanisms. It offers users of the published information label confiance over the absence of irregualrities with the goals of compliance, honesty, and faithful image. The certification by a third party is limited referring to regulated accounting and financial information.

According to definition texts, the certification of accounts doesn't offer external insurance over the quality of the accounting system through the absence of the incidence in the published documents, of the non- compliances regarding important elements.

An accounting quality effort spreads a larger dimension which isn't presently covered by accounting normalization. The accounting quality involves measuring the aptitudes of an entity of providing its clients on- going quality performances, service performances and to indicate to which accounting element the respective measure is applied.

\subsection{Defining the measured accounting object}

Measuring accounting quality imposes defining the „object” which is the subject of the measurement. Two ways can be approached:

- The proceses, procedures and systems of the enterprise, to which an accounting training programme could be applied;

- Restoring different accounting information category, published and used by the enterprise.

\subsection{The discriminating nature of the accounting act}

Similar to any other information, accounting information results in a production process that transforms a cognitive element in a significant message.

Form ancient times till the present, accounting had had as its main manifestation the activity of professionals known by their competence to produce, explore and authenticate economic data quantified and presented according to standardized conventions.

\subsection{Defining the accounting approach}

The accounting activity applied to a quantified economic event is manifested via:

- the identification of the nature of the said event depending on a previously defined typology;

- the classification of the said event according to its nature or destination, depending on a present referential;

- the transformation of the money value according to conventions;

- the assimilation of this event to a certain period of time; 
- a presentation that renders the accounting information faithful and intelligible.

The accounting activity adds to information production and keeping certain restrictions concerning the documentation, archiving, entry transparency, system auditing etc.

\subsection{Delegating accounting acts}

In modern organizations, repetitive operations are usually transformed into decentralized tasks by non-accounting actors, through computerized systems of information handling.

The accounting professional is not content only with knowing and improving the accounting information. He is also interested in the means to obtain that information. Accounting becomes the "crucible" of the managerial and financial information. It must interfere with:

- applying the framework for devising operational decisions (non commercial offers) to accounting rules and graphics;

- devising and operating information means, indicating the philtres of control and coherence of the information distributed by various operational systems;

- the development of the operational life with the goal of post-factum validation of the actual flows of information resulting from the process of accounting centralization, providing synthesis accounting information to internal and external users.

\subsection{Supervising the accounting quality}

The accounting quality of the information made available to users results from the accounting acts that are integrated in the production process of this information. Of course, it has to meet certain previously set features.

The company information system must be structured into processes linked to systems (research, development, production) and a process of synthetic centralization. The quantification of the accounting quality of the returned information shall be done within each process, starting from the expected features of the imbedded accounting acts.

The approach has in view an analysis of the internal functional processes. The quantification of the accounting quality is dealt with as a customer-supplier relation. Internal exchanges or those at the supplier-user interface rely on the defined, formalized and indicated specifications, in order to allow for quality coordination.

The main goal of standardization is basically an interpretation improvement done by the external users of the financial statements. A previous reflection imposes the design of a system of accounting quality assessment that may serve as support in the dialogue between the accounting function and customers, in order to better meet their expectations.

\subsection{Defining the conceptual framework of the accounting quality}

The objectives of accounting quality express a set of features set and undertaken by means of the accounting function of any entity.

There are four orientations known:

- meeting the needs and expectations of the accounting information users in observing the professional norms and ethics;

- continuously improving the accounting information made available, including the communication means;

- efficiency of the accounting information production and communication (presenting the service according to ISO 9004.2);

- taking into account the society and environment requirements.

\subsection{Conceptual frames regarding accountancy and accountancy quality}

Any reflection regarding the notion of accountancy quality requires the prior clarification concerning the outcome of the relation between the accountancy information, its users and the 
described economical reality. The goals of the financial and accounting information, internal or external, consist of rendering accurate data which facilitates the situation's understanding or the acknowledgement of the economic facts, shaped to form an objective assessment, which is useful for the users' decision-making.

The form and content of the accounting-financial information differs according to the users' needs (investors, creditors, internal responsible, company personnel). The rules which define the presentation and content of such information (yearly accounts, issuance prospects, activity accounts) arise either from regulations outside the company or from internal regulations.

External norms are established accountancy agreements, which may be supplemented with the company's regulations. They represent a communication language based on the understanding between accounting information's conveyor and its receiver, which unites the companies and behaviors related to the same economical reality. At the same time, the aforementioned regulations represent the reference system for the products and services rendered by the company's accounting function.

The accountancy's conceptual frame is directed towards the accounting information which must reflect faithfully the described economical reality by means of an accurate enforcement of the accounting agreements. It describes the fundamental goals undertaken by the accountancy. Therefore, it is assured the coherence of the regulations regarding the ascertainment, measurement and presentation, including the design of expressions specific for certain classes of economical, legal operations or for the new financial instruments. Finally, the shaping of the accountancy's conceptual frame allows the determination of the construal of the main accounting principles and fundamental postulates.

\section{Qualitative characteristics of the information, stipulated under financial reports}

The usefulness of the accounting data stipulated under financial reports mainly depends on the following four qualitative characteristics:

\section{- Intelligibility}

It deems that the information must be easily understood by a user who has enough knowledge regarding business fulfillment and, obviously, accountancy knowledge. Obviously, not all information is accessible for any class of users. There is complex data and significant elements stipulated under the financial reports, even though not "everybody" understands them.

\section{- Relevance}

It expresses the information's characteristic to influence profoundly the decision-making process. Thus, there can be assessed the company's capacity to benefit from opportunities and to react quickly to unfavorable situations, namely to adapt itself.

Also, the information's relevance allows the reasonable prevision of the future financial status and performance of the company. In conclusion, the relevant information is the information which helps the users to assess accurately past, present and future events, confirming or correcting their future assessments. In such context, there operates the notion of:

\section{- Significance threshold}

The information is significant if its omission or inaccurate presentation greatly affects the user's economic decisions. The significance threshold rather represents a limit than a primary feature of the information in order to be useful and relevant.

\section{- Reliability}

The information is reliable when it does not contain major errors; it is unbiased, providing enough certain elements in the users' decision-making. The information's relevance feature does not implicitly generate its reliability. Eventual compensation under dispute must not be recorded as such under the balance sheet. It is more adequate to present them under a minute of the financial reports. To be reliable, the information must take into account:

- An accurate representation of the recorded transactions and events;

- The significance of the economic over the legal; 
The events and transactions must be recorded in the registers according to their merits and economical reality and not only by means of their legal form.

\section{- Neutrality}

This feature implies the information to be detached, without any influences. The financial situations are not neutral if, subsequent to information selection and presentation the decision making or the judgment formation is influenced in order to achieve a predetermined goal or objective.

\section{- Prudence}

The incertitude related to many events and enterprise transactions require objectively the issuance of prudent information. The lack in installment of pendency, the use estimated duration of machinery and equipment, eventual complaints correspondent to the sold products, with warranty term are always questionable. To avoid the assets and incomes overvaluation, expenses and debts undervaluation, to which we must add the taking into account of the eventual losses, risks and probable depreciations, are essential dimensions of the prudence principle, naturally blended in accountantship information of the same nature.

\section{- Integrity}

In order to be credible, any information contained within financial books has to be complete, obviously within the reasonable limits of significance threshold together with the cost of procurement exceed by far the risk taken under a random decision. One omission can render the information false or misguidedly and therefore not being reliable any more and becoming defective in relevance.

\section{- Comparability}

Any information is becoming more valuable when it can be compared in time and space, respectively can be related to other reference values. The evaluation of the company's financial state, the performance and the alterations of the financial state imply by default the comparison. Therefore, the recording and the quantification of the financial effect of the same events and transactions must be consequently performed (unitarily), within the same enterprise in time as well as within many enterprises simultaneously. Any alteration occurred in the methods of evaluation and information presentation within financial books must be mentioned in the accountantship policies of the enterprise.

Obviously, the comparability must not lead to immobility and stagnation regarding the accountantship policies.

\section{Limits related to the reliable and relevant information}

\section{- Opportunity}

If there is any exaggerated delay in information report, it can lose its relevance. The management board may be forced to choose between the relative value of reporting to a certain moment and providing reliable information. In order to provide opportune information, it may be often necessary to report all the aspects of a certain transaction or of another event, before these to become wide known, although their reliability is as such affected. On the contrary, if the report is delayed until all the aspects are known, the information is reliable, but its utility is low for the users that had to make decisions meanwhile. In order to achieve a balance between relevance and reliability, the fundamental consideration is the adequate satisfaction of the user's needs when making economical decisions.

\section{- The cost-benefit report}

The cost-benefit report is rather a general coercion than a quality feature. The benefits subsequent to the information should exceed the costs of its delivery. The costs and benefits evaluation represent basically the result of a professional reasoning. Additionally, the costs are not supported by all means by those users that enjoy the benefits. Other users than those the information is ready for can enjoy the benefits; for instance, the delivery of additional information to the creditors could reduce the costs of enterprise binding. Therefore, the cost-benefit test is difficult to 
apply in all particular cases. However, the competent ones in issuing standards, as well as those who draft and use the financial reports should be aware of this limit.

\title{
- Balance between quality features
}

In practice, establishing of a balance between the quality features is often necessary. Generally, the goal is to achieve a proper balance between the relevant qualities in order to fulfill the objective of the financial reports. The relative importance of characteristics in different cases is a professional reasoning problem.

\section{- The accurate image/presentation}

The financial reports have to show an accurate image of the financial state, the performance and the alterations of the financial state of an enterprise. Although this "general framework" does not approach directly such concepts, the enforcement of the main quality features and adequate accountantship standards results as drafting financial reports that reflect generally an accurate image of the enterprise state.

- Patrimony

- Activity/term result

- Financial report

- Economical deeds Accurate image

$$
\text { Departments' decisions }
$$

Accounting information Utility

General agreements (principles, accounting regulations)

User Particular specifications

Qualitative features of the accounting information Intelligibility

\section{Significance \\ Prudence \\ Reliability}

\author{
Neutrality \\ Integrity \\ Comparability
}

The conceptual frame of the accounting information's quality is directed towards the amelioration of the accounting information's utility regarding the decisions or modifications of the user's behavior (see figure no. 1).

The accounting information relates to the external users by means of the financial reports published by the company. The conceptual frame of the accountancy quality defines and construes the parameters which allow the characterization of the accounting information's utility. These generic qualities are distinct and unlikely to be mistaken for the fundamental postulates, main principles and accounting directives for acknowledgment, measurement and presentation which are part of the accounting referential arising from the accountancy's conceptual frame.

The conceptual frame of the accounting quality must be open enough to meet the requirements of both external users (investors, fiscal administration) with regard to the regulated accounting information and to include the particular concerns and specific needs of all the other classes of users.

\subsection{The notion of accounting quality and reference accounting regulations}

The accountantship information does not grant utility to its recipients unless within a conditioning environment that requires an adequate observance of accountancy regulations.

The accountancy regulations define the array of conventions observed in order to express, acknowledge, measure and present the economic reality in accountancy situations. The observance of applicable regulations guarantees the understanding of accountantship situations by the users with enough knowledge regarding the conventions.

The intelligibility of accountancy information is regarded from this point of view and also the consequences of regulations' strict observance. It is implied that the users have sufficient 
knowledge of accounting agreements and of the construal that characterizes the content or form of certain documents regulated or of internal use within the enterprise.

The aforementioned creates a logical relation with regulation definitions and the responsibility to conceive documents with intelligibility approachable to the users. Without being practitioners or experts, the users still have enough knowledge of basic accounting regulations and concepts.

The regulations on accounting quality include not only the external norms that are applied to all the bodies or enterprises issuing accounting information. They also include internal specifications that can be added by those issuing in order to fulfill the specific needs regarding accounting or bookkeeping documents.

The external norms contain the array of accounting rules and agreements extensively defined by the doctrine, regulation or professional practice. These accounting agreements mainly regard:

- fundamental postulates, basic accounting principles and the accounting nomenclature (accounting and financial columns which, in fact, constitute the normalization of the conceptual framework of the accountancy);

- accounting instructions to establish, measure and present (IAS, IFRS, UE norms, national accounting law) whose definition belongs to the national or international law maker who determines where and how to apply them;

- regulations specific to an activity or category of judicial, administrative, technical, economic or financial operations which bring about direct or indirect accounting consequences.

The accounting conventions and rules of foreign origin are completed by internal specifications. The latter establish the ways in which to apply them in a company and organize the meeting of special needs of those who use accounting and administrative data. The regulations or the internal specifications mainly cover the following domains:

- the choice of accounting options to establish, measure, present and define the ways in which to apply the accounting norms within a company;

- accounting classified lists in detail;

- detailed schemes of the accounting of operations;

- the format and the content of unregulated financial, accounting and administrative documents, most of them of domestic use;

- detailed rules which define the affect of incomes and costs per the activities and the products of the company;

- internal ways for documenting the registration and conservation of evidence;

The right application of accounting regulations, of external or internal origin, must be assured by the company's system of "accounting quality". It signifies the guarantee of the conformity of the applied rules in documents as well as the permanent improvement in meeting the users' needs.

The system of accounting quality within the company allows the organization of the fulfillment of the two main objectives, mainly the conformity and the improvement.

\section{Bibliography:}

1. Gogue J. M. - Management de la qualite, 3-e edition Economica, Paris, 2003, p 49-70;

2. Charpentie J. M. - La qualite comptable: cadre conceptuel et criteres de mesure, Revue Fransais de Comptabilite, Mars 1999, p 50-55;

3. Albrech W.S., Stica J.D., Stice E.K., Skousen K.F., Swain M.R. - Management Accounting, $2^{\text {nd }}$ Edition, South Western Thomson Learning, Cincinnati, 2002, p. 367-373. 